Portland State University

PDXScholar

\title{
A Study of the Level of Knowledge of Adult Foster Care Home Providers in Multnomah County in the State of Oregon About Hearing Loss, Hearing Aids and Communication Strategies
}

Marsha Peters Johnson

Portland State University

Follow this and additional works at: https://pdxscholar.library.pdx.edu/open_access_etds

Part of the Communication Commons, Speech and Hearing Science Commons, and the Speech Pathology and Audiology Commons

Let us know how access to this document benefits you.

\section{Recommended Citation}

Johnson, Marsha Peters, "A Study of the Level of Knowledge of Adult Foster Care Home Providers in Multnomah County in the State of Oregon About Hearing Loss, Hearing Aids and Communication Strategies" (1997). Dissertations and Theses. Paper 5378.

https://doi.org/10.15760/etd.7251

This Thesis is brought to you for free and open access. It has been accepted for inclusion in Dissertations and Theses by an authorized administrator of PDXScholar. Please contact us if we can make this document more accessible: pdxscholar@pdx.edu. 


\section{THESIS APPROVAL}

The abstract and thesis of Marsha Peters Johnson for the Master of Science in Speech Communication: Speech and Hearing Science were presented December 7, 1996, and accepted by the thesis committee and the department.

COMMITTEE APPROVALS:
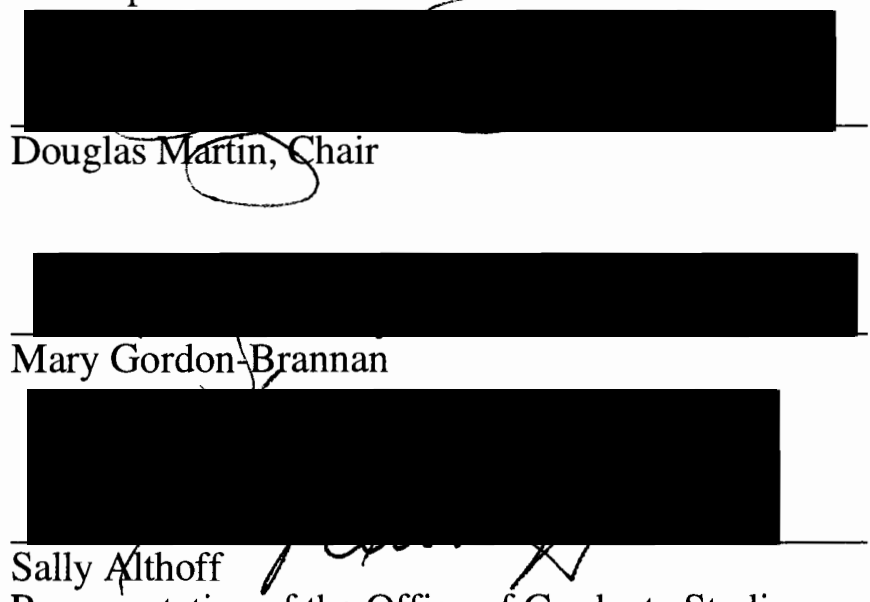

Representative of the Office of Graduate Studies

DEPARTMENT APPROVAL:

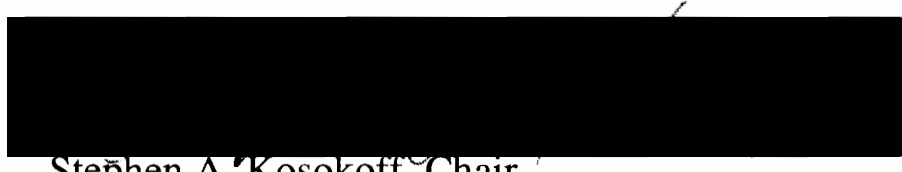

Stephen A.Kosokoff, Chair

Department of Speech Communication

$* * * * * * * * * * * * * * * * * * * * * * * * * * * * * * * * * * * * * * * * * * * * * *$

ACCEPTED FOR PORTLAND STATE UNIVERSITY BY THE LIBRARY

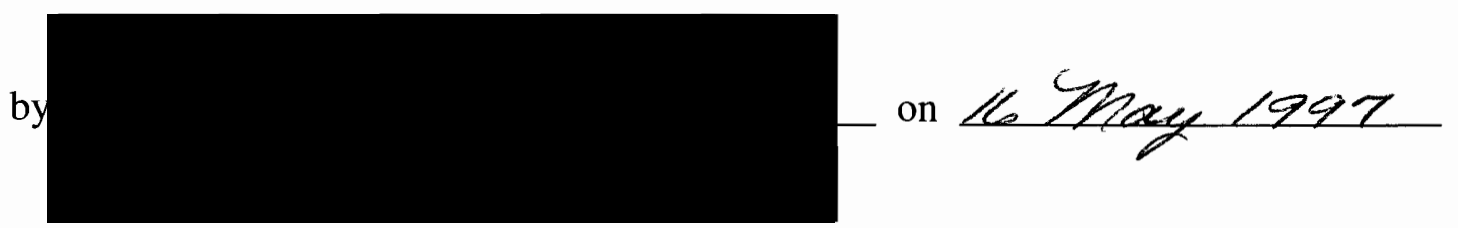




\begin{abstract}
An abstract of the thesis of Marsha Peters Johnson for the Master of Science in Speech Communication: Speech and Hearing Science presented December 7, 1996.

Title: A Study of the level of Knowledge of Adult Foster care Home Providers in Multnomah County in the State of Oregon about Hearing Loss, Hearing Aids, and Communication Strategies.
\end{abstract}

The level of knowledge about hearing aid use, function, and maintenance of caregivers of the elderly persons who are hearing impaired and residing in adult foster care homes in Multnomah County in the state of Oregon was assessed via a 17 question survey. Twenty subjects participated in the study. Subjects' responses demonstrated poor knowledge about this subject and indicated that residents' needs are unmet. The results clearly demonstrate the subjects' limited knowledge of the operation of hearing aids, poor grasp of the basic troubleshooting methods for repair, and inaccurate perceptions of hearing aid adjustment. Access to professional audiologic care and appropriate referral strategies are not in place at this time in the adult foster care system in Multnomah County. Due to a limited sample size, an expanded study is necessary to determine the validity of these findings. However, these results suggest that caregiver education regarding hearing loss and hearing aid use is necessary to ensure comprehensive management of the communication difficulties often experienced by elderly hearing impaired long term care facility residents placed in foster care homes. 
A STUDY OF THE LEVEL OF KNOWLEDGE OF ADULT FOSTER CARE HOME PROVIDERS IN MULTNOMAH COUNTY IN THE STATE OF OREGON ABOUT HEARING LOSS, HEARING AIDS, AND COMMUNICATION STRATEGIES

\author{
by \\ MARSHA PETERS JOHNSON
}

A thesis submitted in partial fulfillment of the requirements for the degree of

MASTER OF SCIENCE

in

SPEECH COMMUNICATION;

SPEECH AND HEARING SCIENCE

Portland State University

1997 


\section{TABLE OF CONTENTS}

\section{PAGE}

LIST OF TABLES

CHAPTER

I INTRODUCTION AND STATEMENT OF PURPOSE ............................

II REVIEW OF THE LITERATURE........................................................

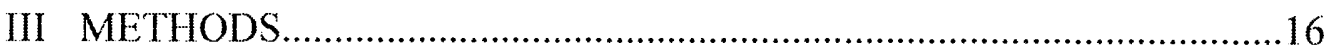

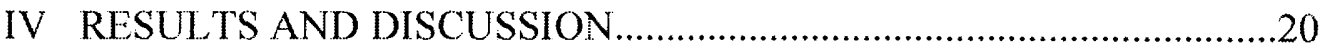

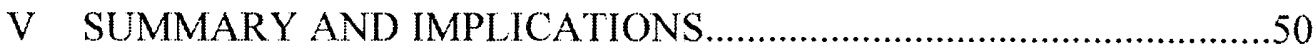

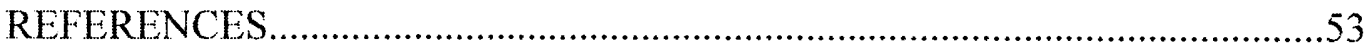

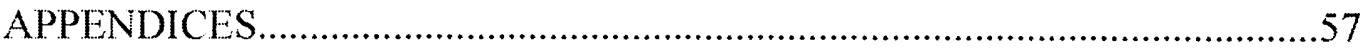
A Informed Consent Form 57

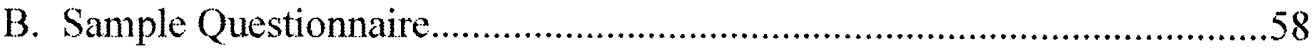

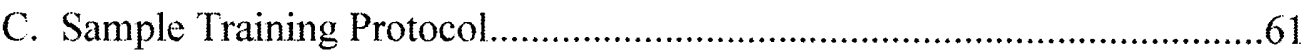




\section{LIST OF TABLES}

TABLE

PAGE

1. Years of experience working with elderly, hours of training credits completed, and estimate of number of current residents at site wearing hearing aids.

2. Subjects' responses to question \#1, describing their experience in working with hearing aids

3. Confidence level of subjects in handling hearing aids of residents of adult foster care home settings. 25

4. Assessing subjects responses to feelings about handling hearing aids of residents of adult foster care homes. 28

5. Abilities of subjects to match hearing aid part names to drawings of hearing aids by subjects. 30

$6 a \& 6$ b. Subjects' responses to questions regarding the comfort level of the subject in inserting and removing hearing aids from the ears of residents, and subjects' responses to provide a description of any concerns about this procedure.

7. Subjects' responses to question \#7 about the cleaning of hearing aids of residents in adult foster care home sites.

8. Subjects' responses regarding simple troubleshooting of hearing aid problems, including feedback or squealing. .36 
9. Responses of subjects about knowledge of hearing aid repair resources, in response to question 9 of survey of adult foster care home caregivers

10. Subjects' responses to question \#10 of survey regarding a description of the process of insertion and removal of batteries from hearing aids. 38

11. Subjects' responses to question \#11 of the survey of adult foster care home caregivers about where to purchase batteries for the hearing aids of residents

12. Responses of the subjects to question \#12 about how long a hearing aid battery should last.

13. Responses of subjects about correctly identifying the earmold part of the hearing aid.

14. Responses of subjects to question \# 14 of the survey in regards to the proper setting of the volune control on a hearing aid of a resident of an adult foster care home. .46

15. Subjects' responses about using strategies for improving communication with elderly hearing impaired residents of adult foster care homes.

16. Subjects' responses to question \#15 about estimating the percentage of residents with significant hearing loss currently residing in their adult foster care home sites

17. Responses of subjects about access by hearing impaired residents in adult foster care home settings to hearing health professionals. 


\section{CHAPTER 1}

\section{INTRODUCTION AND STATEMENT OF PURPOSE}

In the 1980s, a new movement in the geriatric care field began (Miller, 1995). An exodus began as residents of large nursing home facilities moved to smaller facilities designed to provide better, less institutionalized care. In the state of Oregon, individuals who needed supervision and assistance, but not continuous nursing care were selected to move into adult foster care home settings, and, by 1995 , over 8,000 beds in 2,189 commercial homes were available. Health care professionals predicted that the elderly residents' needs would be better served in the smaller facilities which would more closely resemble their lifestyles prior to entering residential care (Miller, 1995).

An added incentive for this change was the anticipated reduction in costs in the smaller settings (Stark, Kane, Kane. \& Finch, 1995). The first adult foster care homes were generally occupied by private paying residents, but in 1981 , the entire system became covered by the state's Medicaid waiver program. In 1995, about two-thirds of the 6,000 adult foster care home residents paid privately, and the rest were covered by Medicaid. The Medicaid payments and the private pay rate for the residents are about. on average, two-thirds of the respective daily rate for large nursing home care (Stark et. al., 1995)

As a result of this exodus, the development of adult foster care homes has accelerated in the state of Oregon, and is now characterized as a model for the nation (Kleiman, 1990). In Multnomah. Washington, and Clackamas Counties in Oregon, adult foster care homes increased from about 100 in 1989 to over 1500 by the end of 1995 (Blackmer, 1994). At present, there are nearly 1800 adult foster care homes 
operating within this area, with many more in various stages of development or construction (Stewart. personal communication, February,1995). Based on this geometric growth rate, a predicted numbers of homes in this area would exceed 18,000 by the year 2000 . At the present time, the homes are limited to a maximum of 5 residents. This means that in the tri-county area, there are approximately 9,000 slots for elderly persons to reside in these settings. According to Multnomah County Department of Aging officials, there is a $10 \%$ vacancy ratio, which means that about 8100 elderly persons are currently in adult foster care homes in this particular area (Stewart, personal communication, 1996).

In 1995, the majority of the adult care home residents in Multnomah County adult foster care homes are over 65 years of age (Blackmer,1994). Studies have confirmed that approximately $60 \%$ of people aged 70 to 74 have a significant degree of hearing loss (Schow \& Narbonne, 1980) and that hearing loss tends to increase with age. It is likely that a significant number of residents in adult foster care homes have hearing loss (Mulrow, 1991). Given that about 8100 individuals currently reside in adult foster care homes in the area, applying the statistical formula cited above, there are as many as 5,000 residents with significant hearing loss within that group (Katz, 1994).

Adult foster care home operation in Oregon is subject to state legislation regarding licensing procedures, which require operator and caregiver training, site preparation and maintenance and which define scope of practice. Each county has jurisdiction over a specific geographical area, with designated staff who supervise, train, and monitor the care home sites. Each county is required to maintain a service for providing timely response to complaints and concerns of residents, operators, and 
families (Immel, personal communication, 1996). Current Oregon state regulations require adult foster care home operators to possess a high school diploma, submit to a criminal background clearance check, and complete an 18-hour training course prior to operating an adult foster care home (Stewart, personal communication, 1995). Required training topics at this time include CPR, recordkeeping, employee practices, and standards of care (Blackmer, personal communication, 1994).

Adults residing in foster care home settings are often homebound, according to the director of Multnomah County Aging Services Department (Stewart, personal communication, 1995). In most of the homes located in Multnomah County, the operators and owners are also the main caregivers for the residents. Stark et. al. (1995) found that foster care home residents rely for the most part on their communicative interactions with caregivers, and other residents to meet their needs for socialization. Residents also rely on their caregivers for assistance in toileting, dressing, bathing, and other personal needs. Currently, adult foster care home caregivers are not required to complete any coursework in the area of resident communication skills. This area could include an understanding of hearing difficulties common in the elderly and how to maximize the use of hearing aids. Other related topics could also be included in the required pre-licensure training coursework

According to the director of services for Multnomah County, residents also need good communication skills to participate in the discussions and decisions regarding care (Stewart, personal communication, 1995). The prevalence of hearing disorders and resulting communication impairment is well documented among the elderly residing in extended care facilities, and may be as high as $82 \%$ according to Schow and Nerbonne (1980). Any disorder affecting speech and hearing will hamper these 
processes, and an understanding of methods to improve the situation by the caregiver is critically important (Stream \& Stream, 1980). In addition, deterioration of communication skills can also have many profound effects on other areas of the person's lifestyle. Chen (1994) found that hearing loss and the ensuing communication difficulties are the cause of isolation, loneliness, anxiety, depression, maladjustment, and frustration. At present, these concerns do not appear to have been addressed in the training protocol for adult foster care home caregivers.

\section{Purpose Statement}

The purpose of this study, therefore, is to assess the level of knowledge of a sampling of current adult foster care home caregivers in Multnomah County as to the use, function, and maintenance of hearing aids, and strategies to improve communication with the elderly person with hearing impairment. Even though these areas are not currently required by county and state legislation for licensing purposes, the value that would be provided to the elderly residents cannot be underestimated. The findings of this study will be used to create a training program at a later date to be used to teach caregivers about these subjects, including how to recognize hearing loss, how to strengthen communicative interactions, how to provide basic hearing aid care and simple troubleshooting of repairs, and how to access appropriate community services to help with the problems.

Therefore, the question that has been created for this research project is: Do adult foster care home caregivers possess adequate knowledge of hearing aid use, function, and simple repair to meet the communication needs of the persons in their care, the elderly adult foster care home resident? 


\section{CHAPTER II \\ REVIEW OF THE LITERATURE}

Previous researchers have studied the topic of geriatric hearing loss and its associated affects for many years, and a review of the literature reveals a rich and varied collection of publications and findings. Many of these studies have been conducted in areas other than the United States, as hearing loss in the elderly is a global phenomena. Currently available research ranges from publications about the social status of the elderly hearing impaired, the prevalence of hearing impairment among the elderly, and the effects hearing loss imposes on the different aspects of day-to-day living. This review of the literature addresses the prevalence of hearing loss among the elderly, effects and types of hearing loss among the elderly, beliefs of caregivers about the effects of hearing loss among the elderly, diagnosing hearing loss and associated difficulties among the elderly, benefits of hearing loss identification and treatment, adult foster care homes' provision of services, and care responsibilities of adult foster care homes.

\section{Prevalence of Hearing Loss Among Elderly in USA}

Approximately 30 million Americans are over the age of 65 according to Katz (1994). Of those 30 million older citizens, approximately $30 \%$ of them probably have some measurable significant, hearing loss. This means that about 10 million Americans over the age of 65 have hearing impairment that affects their ability to communicate effectively.

In contrast to the census data, Quinn (1986) suggested that as many as $60 \%$ of the elderly over age 65 have a significant hearing loss. This study used both audiologic testing and a self-perceived handicap rating by the subject and a significant other to 
determine if the subject was hearing impaired. Self-assessed hearing impairment testing relies heavily on the individual's perception of a hearing handicap or the degree to which the loss contributes to communication difficulties (Stream \& Stream, 1980). The test results could be different than the results obtained through behavioral tests typically administered during an audiologic evaluation. Applying the self-assessed test finding to the census date, the number of hearing impaired senior citizens in this country may be as high as 18 million persons.

Schow and Nerbonne (1980) found that, of elderly subjects residing in extended care facilities, over $80 \%$ showed hearing problems. This higher figure may be a result of other medical conditions which contribute to the overall health status of the subject and have necessitated the institutionalization. Applied to the 9000 elderly residents living in adult foster care home settings in Oregon, 7380 may have significant hearing loss.

\section{Hearing Loss in Elderly}

The majority of elderly adults who suffer from a significant hearing loss (defined as an average threshold at $500 \mathrm{~Hz}, 1000 \mathrm{~Hz}$, and $2000 \mathrm{~Hz}$ of over $25 \mathrm{~dB}$ ) will have a type of hearing loss characterized as sensorineural/presbycusic, which produces permanent threshold shifts in the higher frequencies. Presbycusic loss affects the ability to hear spoken language in the presence of background noise, as well as affects the individual's ability to detect the high frequency components of speech, including voiceless consonant sounds that are critical for understanding (Katz, 1994).

Whereas hearing loss means a loss of hearing acuity in one or both ears, hearing handicap is the individual's response to the hearing loss, which may affect his or her normal functions in daily living (Weinstein, 1982). Hearing handicap is not directly 
dependent upon the measured degree of hearing loss as much as it is the result of the subject's perception of the adverse changes in communication or listening abilities (Katz, 1994).

Other conditions than presbycusic/sensorinerual hearing loss can affect the hearing ability of the elderly. Mahoney (1993) found that up to $34 \%$ of all elderly persons may suffer from one type of hearing loss that is actually reversible, that of cerumen impaction. This type of hearing loss is not always evident upon cursory examination, and can be accurately diagnosed by an audiologic evaluation (Katz, 1994).

\section{Effects of Hearing Loss in Elderly}

Thompson (1993) reported that hearing loss is the third most common chronic condition in elderly people and creates strained relationships with family members and friends. There are many individuals with hearing loss over the age of 65 in this country. The effects of the handicap can be quite variable, depending on the individual. Mulrow (1991) found that hearing loss among the elderly affects many areas of life, including physical skills, cognition, social abilities, and one's sense of well being. Elderly persons with hearing loss in this study were found to spend more time in bed and make more visits to physicians than persons of the same age without hearing loss. The author recommended the use of a self-assessment measure by caretaking staff to screen for undiagnosed hearing losses.

Campbell (1992) examined the relationship between hearing loss and anxiety in its hindrance of communication as a result of the hearing loss. Persons with hearing loss were more likely to experience significant anxiety and distress even in simple. everyday interactions with caretakers and significant others. 
Overall quality of life is also affected by hearing loss as well as the degree of satisfaction with life in general (Etienne, 1990). Satisfaction with life in general decreased as the degree of hearing loss increased, as measured by a self-assessment tool. The researchers speculate on the isolating effect of hearing loss, that serves to remove affected individuals from the mainstream flow of life.

In 1980, Weinstein found that hearing loss contributed significantly to social loneliness in the elderly. He discovered that a causal relationship between peripheral hearing loss and loneliness was significant.

It should not be surprising to note that a significant loss in hearing affects the ability to communicate, thereby affecting all interactions involving communication, even the most minor verbal interactions. Even more specifically, Chen (1994) focused on the changes in activity schedules of elderly patients as a result of hearing loss. A strong correlation was found between severity of hearing loss and amount of activities in this study, thereby reducing further the opportunity for communicative interactions and increasing the restrictive effects of the handicap.

The research reviewed show that hearing loss and hearing handicap contribute to the diminishment of the enjoyment of life, to loneliness and social isolation, and to the elderly's sense of well being (Taylor, 1993). Identification. diagnosis. and rehabilitation could prove beneficial not only for optimal hearing health, but for the ability to perform average daily living responsibilities.

\section{Beliefs of Caregivers About Effects of Hearing Loss in Elderly}

Many nonprofessional and professional health care workers believe that hearing loss is simply a normal part of the aging process and that little can be done to improve the residents' ability to communicate (Mahoney, 1993). This belief leads 
the caretakers of the elderly to ignore or to dismiss the problems associated with hearing loss, and prevents the caretakers from seeking outside help for habilitation.

Often caretakers for the elderly find it frustrating to communicate with the residents with hearing loss in a facility (Jinks, 1991). The caretakers interviewed by Jinks found it extremely difficult to exchange verbal information with patients with hearing impairment. Jinks also discovered that the staff were often unable to recognize the specialized needs of the hearing impaired patients. Jinks recommended that staff need to develop skills and techniques to optimize communication with the elderly residents. This same study also found a significant delay for seeking audiologic care on the part of the patient, with 10 years or more elapsing between the onset of hearing loss and the first date of audiologic services. These conclusions would tend to support the idea that even if the hearing loss is recognized by the patient and/or the staff of a care facility, few options are made available for remediation.

Some caregivers do not believe that the detection of hearing loss is their responsibility, as Brannon. Smyer, and Cohn (1992) discovered in an investigation of nursing home care practices. Staff at residential facilities were found to be charged with "contradictory instructions and blurred accountability" (Brannon et al., 1992. p. 20 ) as the result of the criteria used to define quality of care differed within their organizations. The challenge to health care providers in these settings is to discover methods to accommodate the residents' basic needs while also taking responsibility for other equally important health concerns.

Diagnosing Hearing Loss in Elderly \& Associated Difficulties 
Standard audiologic testing procedures are used to detect hearing loss in the elderly, while maintaining awareness of the potential for inaccurate results due to fatigue and cognitive deficits on test results which are often a concern when assessing this population (Katz, 1994). However, audiologic testing requires transportation to a special site to take place in a sound treated booth with calibrated equipment. This may not be economically feasible or physically possible for all patients suspected of hearing loss.

When an elderly person finally seeks audiologic care, communication between the audiologist and the patient is often not optimal (Martin, Krueger, \& Bernstein 1990). Verbal exchanges are often incomplete and do not lead to the best diagnosis on the part of the audiologist, and the authors urged a training program be implemented to provide all core professionals who work with the elderly to improve perception and counseling skills.

Currently the American Speech-Language-Hearing Association (ASHA), the governing body for audiologists, publishes guidelines for assessing hearing impairment/handicap in adult elderly persons which include conventional audiometry, tympanometry screening, and the use of the Hearing Handicap Inventory for the Elderly (HHIE). This approach was studied for its appropriateness and difficulty of administration by a team of researchers in 1993 (Ciurlia-Guy, Cashman, \& Lewsen, 1993). This study found that use of all three methods proved helpful in the diagnosis of hearing loss in this population. However, most of these tests require a visit to an audiology clinic so the testing can take place in a sound treated room. 
Informal screening tests are also available for use by other health care professionals and should be taken into consideration for use in adult foster care home settings. Mulrow (1991) found that the use of a whispered voice, a tuning fork test, a rubbing sound from fingers held near the ear, and a portable audioscope were all relatively easy and effective ways of obtaining a gross measurement of hearing acuity in the elderly patient. She discovered that the sensitivity of the whispered voice test, where the caregiver says six test words at a range of 6 to 24 inches from the ear, with the other ear occluded by having the patient gently press on the tragus, ranged from $80 \%$ to $100 \%$ and specificity was $82 \%$ to $89 \%$. Specificity and sensitivity of a test refer to the degree of accuracy of the diagnosis, to the validity and reliability of the test results. Self-assessment measures were also used to screen quickly for a moderate-to-severe hearing handicap, and were found to have a sensitivity of $30 \%$ to $70 \%$, and a specificity of $80 \%$ to $90 \%$. Most of these techniques are easily taught and quickly learned, and could be of great use in the adult foster care home setting.

Newman (1990) investigated the possibility of using a nurse-administered screening test for hearing in residential care settings for the elderly. She developed a hearing assessment test, consisting of a self-assessment instrument, a spoken word discrimination test, an identification task while listening to tape-recorded environmental sounds, and observation of behavior during the task completion by the nurse. She compared the results of the hearing assessment test with standard audiometric evaluation results and found that results were favorably related, especially in the areas of sound identification and behavioral observation. She concluded by stressing the need for caregivers of the elderly to enable the patient to maximize the ability to communicate within an optimum listening environment. 


\section{$\underline{\text { Benefits of Hearing Loss Identification \& Treatment }}$}

Fortunately, persons with prebycusic hearing loss often find relief with the use of hearing aids, depending on four factors, according to a study by Patterson and Dancer (1987). These factors include the aging process, the severity of the hearing loss, the understanding of how the use of an amplification device fits into the communication process, and the personal motivation of the person to use the device. Conveying information from the audiologic professional and the elderly recipient is critical to the successful use of any amplification device. According to this study, information provided to the caregivers is equally important in attaining the highest benefit from the hearing aid device.

Even elderly residents who are in the early stages of dementia may benefit from the identification and remediation of hearing loss (Matteson, 1993), as improving the sensory skills apparently aided in helping the person communicate more effectively. One might conclude from this study that persons with decreased sensory efficacy of any type might be more likely to lose 'touch' with the world. Kreeger, Raulin. Grace, and Priest (1995) reported that gradual hearing loss may prevent the accurate assessment of psychopathology in geriatric psychiatric patients. It was discovered that the use of hearing aids permitted the patients to score higher than when similar tests were administered while the patients were not using their hearing aids. This information seems to emphasize the need to conduct accurate, early tests for hearing loss in order to stave off some of the negative consequences of ignoring hearing impairment in the elderly.

Swagerty (1995) found that hearing loss can profoundly affect physical, psychological, and cognitive function, which may be reversed by the use of 
appropriate amplification device. He recommended a comprehensive audiologic assessment prior to the selection of hearing aid and extensive aural rehabilitation to follow. Trumble and Piterman (1992) also suggested the use of audiometry for screening purposes for elderly patients, and found that the rate of discovery of hearing impairment is very high in that particular population.

Adult Foster Care Home: Provision of Health Services for Elderly

The literature is silent in regards to the effects of hearing loss on residents of adult foster care homes. According to a study conducted in1992, over one million elderly persons were living in over 41.000 licensed foster homes and over 34,000 elderly were residing in states where foster care facilities are not required to obtain licensure (Warshaw, 1992). The literature does not provide research to demonstrate that these individuals have adequate access to health services, including hearing testing. There is no prescribed process for referral for these services.

Lindblade and McDonald (1985) suggested that it is the caregiver, in their study, nurses, who have the most important role in identifying the patients who were experiencing hearing loss, and could provide information and assistance to reduce the impairment level. For the adult foster care home resident, the operator is the main caregiver, and should be able to recognize and offer assistance to residents with hearing impairment,

Referral for a hearing test for an elderly person most often originates with a relative or close associate, according to Anderson, Dancer, and Durand (1990). In the adult foster care home setting, the caregiver is the person who would qualify as the close associate, and should be able to recognize hearing loss to generate the referral. Whether this happens is unclear due to lack of data available. 
Residents may be able to be screened in their adult foster care homes if the provider has been trained to administer a simple pencil and paper test. Using the Hearing Handicap Inventory for the Elderly (HHIE) to quantify emotional and social effects of self-perceived hearing loss in 100 elderly subjects was the purpose of a study conducted by McBride, Mulrow, Aguilar, and Tuley (1994). The qualitative data gathered from the inventory was just as important as standard audiometric data when used to help counsel the subjects about the effects of their hearing loss Other researchers found the HHIE very useful as a screening tool prior to audiologic examination (Weinstein. Spitzer, \& Ventry, 1986). Perhaps adult foster care home staff could be trained to use a combination of simple screening tests and a selfassessment tool to probe for confirmation of concerns about hearing loss in residents.

Care Responsibilities of Licensed Foster Care Homes: Monitored Activities

State inspectors and county licensing agents, at this time, check for seven major areas in their monitoring of the adult foster care home sites. These seven activities are considered to form the basic necessities for daily living and include: continence, feeding, toileting, transferring, mobility, dressing, and bathing ( Stark et al., 1995). According to county inspectors, an informal evaluation based on resident's verbal responses is conducted to judge satisfaction with setting, discern problems, or to determine additional monitoring needs (Stewart, personal communication, February, 1995). There is no requirement in place for the provision of hearing and speech services, assessments, and assistance.

\section{Summary}

It is clear that there is a pressing need for providing hearing assessment and rehabilitative services to the elderly, who are likely to have a significant degree of 
hearing loss. Hearing care is particularly important for those persons who reside in long term care facilities, whether large institutions or small adult foster care homes. The training and preparation to operate the home settings is not adequate in this area, and may provoke negative consequences for the elderly residents who will suffer from the associated disadvantages of hearing loss including social isolation, depression, and cognitive deficits. Adult foster care home caregivers have a responsibility to provide for the hearing needs of their residents. Caregivers of the elderly should strive to achieve the highest possible communicative environment. 


\section{CHAPTER III}

\section{METHODS}

A survey format was chosen to be the basic information gathering device for this descriptive thesis. The target population for this study are individual adult foster care home caregivers, who are most often the owners of the home site. Adult foster care homes were widely distributed in the selected geographical region under study in this investigation, which included a tri-county area: Multnomah, Washington, and Clackamas Counties. Therefore, it was decided to use homes located in Multnomah County only. Due to the multitude of responsibilities of the caregivers, and the scheduling difficulties anticipated in meeting face-to-face at the different sites, it was decided to use the postal system for the delivery and return of the surveys.

\section{Subjects}

Potential subjects for this study were obtained from a list of all licensed adult foster care homes provided by the Multnomah County Department of Aging Services in Oregon. At this time the state of Oregon and Multnomah County work cooperatively to provide a licensure procedure for adult foster care homes.

Maintenance of licensure requires periodic inspection of the site by state and county representatives, completion of training by the caregivers, and filing of regulatory documents with the county and state offices. Licenses are renewed on an annual basis. Only foster care homes with current licenses were included in this study. Therefore. a list of potential subjects was obtained from the list of licensed home sites in Multnomah County.

Two adult foster care home subjects were selected from the list of potential subjects to participate in the development and modification of the questionnaire. 
The list of potential subjects was again reviewed to avoid duplication or multiple questionnaires since a certain number of subjects are often in charge of more than one site. Using a numbering system, subjects were assigned a number at random, in order to prioritize the order in which subjects would be selected for participation. With 516 total homesites on the original list provided by Multnomah County, 468 were selected for the potential subject list after multiple site owners were eliminated. Two sites were selected at random for use in the pilot interview process. The 466 remaining potential subjects were assigned a number, at random, from 1 to 466 , to create a system for study inclusion purposes.

\section{Instrumentation}

An initial questionnaire was created for use in pilot interviews with two foster care home subjects selected. These pilot interviewees were given the opportunity to complete the questionnaire. A discussion time followed the completion to review the document, and the subjects were asked to point out any unclear tasks or questions. The results of the discussion were used to revise the format of the questionnaire in the areas where the questions were not clear. A major change from the original format involved the shifting from all multiple choice, closed set questions to many open set questions, with the intention of gathering additional knowledge. Closed set questions offer a limited number of choices in response to a questions, whereas open set questions leave a blank line for a response which requires a written answer. Open set questions probe for the information that the test-taker has at his disposal, whereas closed set questions provide possible answers and forces the test-taker to make a choice. 
The change was motivated by a concern about the adult foster care home caregiver's ability to understand much of technical terminology associated with the field of audiology and hearing aids. Open set questions also allowed the subjects to respond with a variety of answers, and could provide more information.

The revised questionnaire consisted of 17 questions with sections inquiring about knowledge of hearing aid design. function, repairs, troubleshooting, and maintenance (Appendix A). In addition. several questions were posed regarding the caregiver's perception of hearing impairment, hearing loss, and communication strategies. Questions were structured into multiple choice, short answer, and matching styles.

Open set questions were deliberately included for the purpose of seeking information about the subject's perception of the effects of hearing impairment. Collecting information about the methods that the subject currently uses to overcome communication barriers was also deemed important.

The language and vocabulary of the questionnaire was purposefully kept as simple as possible in order to accommodate the large number of non-native English speakers who operate many of the adult foster care home sites in Multnomah County (Stewart, personal communication, February, 1995).

\section{Procedures}

The revised questionnaire was sent to 60 adult foster care home subjects, with a self-addressed, stamped return envelope, a consent form, and a cover letter with instructions (See Appendix B). Sixty subjects were chosen from the list of foster care homes in Multnomah county. The subjects were to complete the questionnaire without assistance from other staff members or family, and were encouraged to return the form as soon as possible. Subjects who did not return their forms within 
15 days were mailed a reminder card. Subjects that did not respond to the reminder card received a telephone call if the form was not returned within 25 days of the initial mailing date. Six responses were received from the first mailing. After 25 days, 54 subjects received a reminder call. Out of the remaining 54 possible subjects, 2 returned completed surveys, following repeated telephone reminder contacts.

Due to the very low response rate, it was decided to continue to select new subjects at random, and an additional 58 surveys were sent out to new subjects. Four completed surveys were received within several weeks. Post card reminders were sent out to 54 subjects. Reminder calls were placed after the 25 th day following the mailing of the second group of subjects, and 8 more completed surveys were received. The total number of surveys returned was 20 out of the 158 , which is a return rate of $17 \%$.

During the reminder calls, information was received from the subjects regarding the many reasons why they did not wish to participate in the survey. At least 10 of the subjects were not able to be contacted by telephone, as the identified owner was not available, or an answering machine was the only means of contact, and phone messages were not responded to.

To summarize, due to a poor initial response, it was necessary to mail out 118 surveys over the course of 5 months, and many telephone calls were made to encourage the return of the surveys. The return rate was $17 \%$, as only 20 of the surveys were received. 


\section{CHAPTER IV}

\section{RESULTS AND DISCUSSION}

One hundred and eighteen surveys were mailed to selected adult foster care home subjects in Multnomah County during the months of June, July, and August 1996. Twenty were completed and returned. Telephone calls to request the return of outstanding surveys resulted in the informal gathering of many different reasons why the subjects declined to participate. The most common reason given for a decline was the fact that the study was not required to operate or license a foster care home and, therefore, the subjects did not wish to participate. The second most common reason given for a decline was lack of time. The third was a lack of interest.

With twenty surveys returned out of one hundred and eighteen originally sent, a return rate of $17 \%$ was attained. Each survey returned represented a different adult foster care home subject. No personal or identifying information was collected, and each subject was, therefore, anonymous.

\section{Experience of Caregivers}

Table 1 presents the information gathered from the heading of the survey: questions s about the years of training and hours of credits acquired by the subjects, and an estimate of how many of their residents were currently using hearing amplification. According to the results, the number of years and hours of credits obtained by the adult foster care home subjects was very close to that required by Oregon state law for continued licensure. Care home operators are required to obtain 10 hours of continuing education credits each year, and a wide variety of classes are offered through the county offices and by private educators (Stewart, personal communication, 1995). The average time spent working with the elderly was almost 
9 years, and the average number of credits was almost 80 . It should be noted that some of the subjects wrote in comments about having worked in nursing homes or rehabilitation centers and that time was included in the answer, which may have skewed the results.

\section{Numbers of Residents Using Hearing Aids at Sites}

The average of almost 1 resident out of 5 possible residents using hearing aids was unexpected, as it does not correspond well to the predicted data of the literature review, which placed the potential number of elderly residents with hearing loss at a much higher average, from $60 \%$ to $82 \%$, or 6 to 8 out of 10 residents, who could receive benefit from hearing amplification. However, there may be many other factors involved including socio-economic concerns of residents who cannot afford amplification devices, access to medical services by residents, perceived benefits or limitations of amplification devices, and staff support of caregivers in maintaining the devices or access to audiology services.

According to the literature, there may be many facets of a person's life which can negatively affected by hearing loss (Campbell, 1992; Etienne, 1990; Thompson, 1993). The reported low number of hearing aid users residing in Multnomah County foster care homes may reflect several possible explanations. It could mean that the residents who have hearing impairment do not have access to services, or that they do not choose to take advantage of services. It could also mean the residents have hearing loss but do not wear hearing aids. The reported figure may also reflect national trends in the use of hearing aid devices among the elderly, which is estimated at less than $10 \%$ of market penetration, which compares actual purchasers against those who may benefit from hearing amplification (Katz.1994). 
Table 2 shows the subjects' responses to question \#1 of the survey, describing the experience level of the subjects in working with hearing aids. The question was constructed as an open set question. It is clear that few of the subjects have extensive experience with hearing aids, which is a little surprising given that the average number of years that a subject has worked with elderly patients is almost 9 years. Many answers received from the subjects mentioned working with residents and hearing aids, family members with hearing aids. or cited a limited on-the-job experience with hearing aids.

Table 3 summarizes the respondents confidence in actually handling the hearing aids. According to this information, over half of the subjects describe themselves as feeling comfortable handling hearing aids. This contradicts with the information presented in Table 2 in which about 14\% described their experience with hearing aids as anything other than limited. The other half of the subjects were either unsure or definitely not confident with the task. As the word "handling" was not defined in detailed terms, it could have been interpreted to mean touching to remove and insert aid into an ear, or a full range of remedial activities including repair, adjustment, and cleaning. These results would support the need for further training in this area for caregivers of the elderly adult foster care homes.

Table 4 is displays information regarding the feelings of the subjects about handling the hearing aids of residents. The results show that the subjects $(74 \%$ or 17 out of 20 subjects) seem to consider handling hearing aids as part of their job duties. However, almost $30 \%$ indicated that they had concerns about this task, and 
Table 1. Years of experience working with elderly, hours of training credits completed, and estimate of number of current residents at site wearing hearing aids $(\mathrm{n}=20$ subjects).

\begin{tabular}{|l|l|l|}
\hline Response categories & Total & Mean \\
\hline $\begin{array}{l}\text { Number of Years of } \\
\text { Experience }\end{array}$ & 178.5 years & 8.9 years \\
\hline $\begin{array}{l}\text { Number of Hours of } \\
\text { Training }\end{array}$ & 1,578 hours & 78.9 hours \\
\hline $\begin{array}{l}\text { Number of Residents w/H. } \\
\text { Aids }\end{array}$ & 19 residents & $\begin{array}{l}.95 \text { resident per } \\
\text { site }\end{array}$ \\
\hline
\end{tabular}


Table 2. Subjects' responses to question \#1, describing their experience in working with hearing aids $(n=26)$.

\begin{tabular}{|l|l|l|}
\hline Response categories & $\%$ Responses & Number of Responses \\
\hline Very limited experience & $19 \%$ & \\
\hline Only with residents & $15 \%$ & 5 \\
\hline Bad experience, no success & $15 \%$ & 3 \\
\hline Working in a nursing home & $15 \%$ & 3 \\
\hline No response & $15 \%$ & 3 \\
\hline Remove \& insert only & $8 \%$ & 3 \\
\hline No experience & $8 \%$ & 2 \\
\hline Only adjust volume & $8 \%$ & 2 \\
\hline Family member has h. aid & $4 \%$ & 2 \\
\hline Can change tubing only & $4 \%$ & 1 \\
\hline
\end{tabular}


Table 3. Subjects' responses to question $\# 2$ about their confidence level in handling hearing aids of residents in adult foster care homes $(n=20)$.

\begin{tabular}{|l|l|l|}
\hline Response Categories & Percentage of Responses & $\begin{array}{l}\text { Number of } \\
\text { Responses }\end{array}$ \\
\hline Confident & $55 \%$ & \\
\hline Somewhat confident & $25 \%$ & 11 \\
\hline Not confident & $20 \%$ & 5 \\
\hline
\end{tabular}


worry about the consequences of their actions. Hearing aids are known to be expensive devices and the concern about damaging the small instrument combined with lack of knowledge about its operation may have created the responses to choices $\underline{a}$ and $\underline{b}$.

Question 4, an open-ended question, requested the subjects to propose based on their own experience why elderly adult foster care home residents may not wear prescribed hearing aids. Answers to this question varied widely and the many different responses are presented here in the following paragraphs, in an anecdotal form.

The most common response ( 5 subjects) was that elderly hearing impaired individuals do not find hearing aids useful with the added comment, "they (meaning the residents) don't think it helps much." Another added "not only are they uncomfortable to wear, but they amplify sounds that people can't quite understand, and this is irritating." .

Another subject who noted that the ringing and whistling was so annoying that the resident did not wish to wear the aids. Another added that the residents just cannot get used to hearing aids and that older people are easily confused by the hearing aids. One subject wrote that the residents in many homes suffer from dementia and hearing aids create more of a problem than a help. Several others commented that the residents are used to poor hearing and have become accustomed to living with hearing loss. One subject responded that the residents get nervous when wearing their aids, and seem to prefer silence. 
A negative side effect often mentioned was the fact that hearing aids amplify background sounds and the residents then complain about the resulting noise levels in the homes. Hearing aids that cause pain were also the cause of discontinued use. Another reason cited was the fact that many residents lie in bed, and the hearing aids hurt their ears or might be broken in the bed. One subject mentioned that stroke victims cannot insert or remove the aids, therefore they are not worn. Several others mentioned how the poor dexterity that is common in the elderly makes it difficult to insert or remove, replace batteries, and adjust the hearing aids.

Forgetfulness or misplacing the hearing aid somewhere in the room or the home was another response. A poor fit was cited by a subject with the comment that the volume control was difficult to set properly. "Hard to manage" was another response, which makes sense in light of the many existing responsibilities of the home operators, as was "can't make it work". Shame or pride was also cited as a reason why residents do not or will not wear their hearing aids.

In analyzing the responses to this question, it appears the subjects provided examples of nearly every rationale for not using or wearing hearing aids by hearing impaired of all ages. Their responses paint a very telling picture of the truth about hearing aid use by the elderly. Despite the positive attributes of hearing aids, many users apparently find their usefulness to be less than ideal, with deficits in comfort or poor sound quality or clarity. Kochkin (1996) found that despite substantial growth in sales in recent years for the hearing aid market, sales penetration of the potential market continues to be stagnant. User satisfaction has declined to $53 \%$ for 
Table 4. Assessing how subjects feel about handling hearing aids of the residents in adult foster care homes $(n=20)$

\begin{tabular}{|l|l|l|}
\hline Response categories & Percentage of responses & Number of responses \\
\hline a) makes me nervous & $9 \%$ & 2 \\
\hline $\begin{array}{c}\text { b) might damage hearing } \\
\text { aid }\end{array}$ & $15 \%$ & 3 \\
\hline c) is part of my job & $74 \%$ & 17 \\
\hline d) is not part of my job & $4 \%$ & 1 \\
\hline
\end{tabular}


all types of hearing aid devices despite claims of advances by hearing aid manufacturers about new technology. With additional training, the subjects in this study would be able to adjust the hearing aids more accurately, thereby providing the adult foster care home residents with optimal benefits. This could increase the likelihood that the residents would wear the hearing aids and improve their communication abilities.

Table 5 presents data on the picture identification of hearing aid parts matching question which was included to assess the ability of the subjects in correctly locating various hearing aid parts in two different styles of hearing aids. In reviewing the results in table 5 , probably the most common error in identifying the parts of a hearing aid was found in locating the microphone port. Most subjects could identify the battery compartment and volume controls, which are much more important in terms of care and adjustment. The in-the-ear (ITE) hearing aid seemed to be easier to identify than the behind-the-ear hearing aid. Most subjects could correctly locate the most important parts of the hearing aids. The significance of the responses to this question is that most subjects were able to identify the two important parts of the hearing aids: the volume control and the battery door, which are critical when providing assistance to the elderly residents.

Tables $6 \mathrm{a}$ and $6 \mathrm{~b}$ show subjects' responses to questions about the comfort level of the subjects in inserting and removing hearing aids from the ears of residents, and a description of any concerns about the procedures. The subjects clearly seem to have confidence in their ability to insert and remove 
Table 5. Subjects' responses to matching hearing aid parts on a diagrams to the proper names of the parts $(n=20)$.

\begin{tabular}{|l|l|l|}
\hline Response Categories & Percentage of responses & Number of responses \\
\hline & & \\
Correct Matching & $30 \%$ & 6 \\
\hline Incorrect Matching & $40 \%$ & 8 \\
\hline Blank/No response & $30 \%$ & 6 \\
\hline
\end{tabular}


Table 6a. Subjects` responses to question 6 a, regarding the comfort level of the subject in inserting and removing hearing aid from the ears of residents of adult foster care homes $(n=20)$.

\begin{tabular}{|l|l|l|}
\hline Response categories & Percentage of responses & $\begin{array}{l}\text { Number of } \\
\text { responses }\end{array}$ \\
\hline Comfortable & $90 \%$ & 18 \\
\hline Not comfortable & $10 \%$ & 2 \\
\hline
\end{tabular}

Table $6 \mathrm{~b}$. Subjects' responses to question $6 \mathrm{~b}$, where a description of any concerns about the insertion and removal of the hearing aids was requested.

\begin{tabular}{|l|l|l|}
\hline Response categories & Percentage of reponses & Number of responses \\
\hline Have never done this & $5 \%$ & 1 \\
\hline Causes pain & $5 \%$ & 1 \\
\hline Concerns about insertion & $5 \%$ & 1 \\
\hline Afraid to drop it & $5 \%$ & 1 \\
\hline $\begin{array}{l}\text { No concerns, want to } \\
\text { help residents }\end{array}$ & $5 \%$ & 1 \\
\hline No response & $75 \%$ & 15 \\
\hline
\end{tabular}


hearing aids as over $90 \%$ chose the comfortable response to part $6 \mathrm{a}$. It appears that as part of their association with elderly residents, inserting and removing hearing aids has been included. Only $1 / 4$ of the subjects chose to enter a written comment about concerns about the procedure.

Table 7, entitled "Subjects' responses to question \#7 about the cleaning of hearing aids of residents of adult foster care homes, chosen method of cleaning hearing aids", presents data collected when subjects were given a closed set of answers. The correct answers are $c$ ) with a paper towel or tissue, or b) using a hearing aid cleaning solution that is provided by some hearing aid manufacturers. About $1 / 3$ of the recipients chose the best two answers, and there may be legitimate reasons why some of the others were selected. One of the respondents called to ask if the question in the survey referred to an ITE hearing aid or a behind-the-ear (BTE) hearing aid. This is a legitimate concern as the BTE hearing aids have a detachable mold portion. constructed of plastic, that can be removed and washed in hot soapy water and dried. It is impossible to judge if other subjects in this study were thinking of the same question. The number of subjects $(33 \%)$ who did not know how to clean a hearing aid or chose response e) they should not be cleaned is of more concern as these individuals do not recognize the important of daily maintenance as an important part of maintaining the optimal functioning of the hearing aid. This question and the responses demonstrate the need for training in this area due to the percentage of respondents choosing incorrect responses.

Information presented in Table 8 shows the subjects' responses to Question \#8 which asked for reasons why hearing aids produce feedback. Half of the subjects were able to choose a correct response to the question. It appears that most of the 
subjects know the cause of feedback in hearing aids and know the appropriate steps for remediation. Many of the answers also indicate that the subjects are aware of at least one appropriate action which will correct the feedback or squealing. For the other subjects who either didn't know or expressed incorrect answers, training in this area and an explanation of the process that creates feedback would be helpful.

The next questions, \#9, inquired as to repair service that would be used if a resident's hearing aid is broken. The responses to the question shown in Table 9 indicate that the adult foster care home operators have a relatively accurate idea of whom would provide a repair service for broken hearing aids. The answers also show that there is an appropriate system in place to handle problems that arise with patient care not directly under their control. Accessing any one of the cited resources would probably result in the proper treatment for the resident. It would appear, therefore, that this is an area where the home operators do not require additional information in order to conduct their jobs adequately.

Table 10 presents information gathered from subjects' responses to the question of how to insert and remove a hearing aid battery. Battery replacement is the most often performed task associated with a hearing aid other than volume control manipulation, and it is required for normal hearing aid function (Fausti, personal communication, October,1996).

As shown in Table 10, more than half of the subjects correctly described how to insert and remove the battery of a hearing aid. The remaining subjects did not describe the procedure correctly while one subject indicated that it was not in the scope of their job description. Part of the difficulty with answering this question was the apparent difficulty with the survey wording for some of the subjects, who 
may have been non-native English speakers. It is possible that some of these subjects could complete insertion and removal of the battery during a hands-on demonstration. However, the results would indicate that this is an area that needs to be reviewed for home care operators in a training course.

Table 11 shows the results of assessing the subjects' level of knowledge about where to purchase hearing aid batteries. The results presented in Table 11 indicate an awareness on the part of the care providers of appropriate places to purchase batteries for hearing aids. Overall, though. these results show a good grasp of the topic.

Even though subjects know where to purchase batteries for their clients, according to the data in Table 12, ideas about how long the hearing aid batteries should last are widely variable. Over $45 \%$ of those polled who answered "don't know" or "1 year" obviously have an inaccurate idea of the approximate length of a hearing aid battery life. This is a very important question because an elderly resident with binaural hearing amplification may not be able to detect when one of the hearing aids needs a new battery. The care provider must be aware of the approximate battery life of a specific hearing aid, which can vary depending on the internal components of the aid, so that the time to insert a fresh one can be estimated.

Probably part of the reason that so many different answers were given is due to the fact that the life of hearing aid batteries tends to depend on the type of hearing aid and the current demanded for its operation. Over half of the subjects offered justifiable answers, and could be considered knowledgeable about the life of hearing aid batteries. Inclusion of the topic in a training program is warranted, however, due to the evident confusion. 
Table 7. Subjects" responses to question \#7 about the cleaning of hearing aids of residents of adult foster care homes.

\begin{tabular}{|l|l|l|}
\hline Response categories & Percentage of responses & $\begin{array}{l}\text { Number of } \\
\text { responses }\end{array}$ \\
\hline $\begin{array}{l}\text { With soap and warm } \\
\text { water }\end{array}$ & $12 \%$ & 3 \\
\hline $\begin{array}{l}\text { With a commercial } \\
\text { cleaner }\end{array}$ & $8 \%$ & 2 \\
\hline $\begin{array}{l}\text { With a tissue or paper } \\
\text { towel }\end{array}$ & $32 \%$ & 8 \\
\hline Soak them, then dry & $4 \%$ & 1 \\
\hline Do not clean & $12 \%$ & 3 \\
\hline No response & $20 \%$ & 5 \\
\hline $\begin{array}{l}\text { With a toothpick \& } \\
\text { brush }\end{array}$ & $12 \%$ & 3 \\
\hline
\end{tabular}


Table 8. Subjects' responses regarding simple troubleshooting of hearing aid problems, including feedback or squealing.

\begin{tabular}{|l|l|l|}
\hline Response categories & Percentage of reponses & $\begin{array}{l}\text { Number of } \\
\text { responses }\end{array}$ \\
\hline Volume control too high & $40 \%$ & 10 \\
\hline Do not know answer & $24 \%$ & 6 \\
\hline Should adjust h. aid & $16 \%$ & 4 \\
\hline H. aid not in ear right & $4 \%$ & 1 \\
\hline Tells if h. aid working & $4 \%$ & 1 \\
\hline H. aid hurting ears & $4 \%$ & 1 \\
\hline Needs a battery & $4 \%$ & 1 \\
\hline Earwax in ear canal & $4 \%$ & 1 \\
\hline
\end{tabular}


Table 9. Responses of subjects about knowledge of hearing aid repair resources, in response to question $\# 9$ of survey of adult foster care home caregivers.

\begin{tabular}{|l|l|l|}
\hline Response categories & Percentage of responses & $\begin{array}{l}\text { Number of } \\
\text { responses }\end{array}$ \\
\hline $\begin{array}{l}\text { Return to place of } \\
\text { purchase or seller }\end{array}$ & $36 \%$ & 8 \\
\hline A special shop & $18 \%$ & 4 \\
\hline Don't know/no idea & $14 \%$ & 3 \\
\hline A repair shop & $9 \%$ & 2 \\
\hline Miracle Ear shop & $4.5 \%$ & 1 \\
\hline $\begin{array}{l}\text { Give to the family of } \\
\text { resident }\end{array}$ & $4.5 \%$ & 1 \\
\hline Give to a doctor & $4.5 \%$ & 1 \\
\hline Willoughby's & $4.5 \%$ & 1 \\
\hline Gresham Hearing Center & $4.5 \%$ & 1 \\
\hline
\end{tabular}


Table 10. Subjects' responses to question $\$ 10$ of survey regarding a description of the process of insertion and removal of batteries from hearing aids.

\begin{tabular}{|l|l|l|}
\hline Response categories & Percentage of reponses & $\begin{array}{l}\text { Number of } \\
\text { responses }\end{array}$ \\
\hline Do not know/not sure & $35 \%$ & 7 \\
\hline Correctly described & $60 \%$ & 12 \\
\hline Not my job & $5 \%$ & 1 \\
\hline
\end{tabular}


Table 11. Subjects' responses to question \# 11 of the survey of adult foster care home caregivers about where to purchase batteries for hearing aids of residents.

\begin{tabular}{|l|l|l|}
\hline Response categories & Percentage of responses & Number of responses \\
\hline & & \\
Pharmacy/drugstore & $44 \%$ & 11 \\
\hline Fred Meyer's & $15 \%$ & 4 \\
\hline Miracle Ear Shop & $11 \%$ & 3 \\
\hline Costco & $7 \%$ & 2 \\
\hline Don't Know & $7 \%$ & 2 \\
\hline Family Provides & $4 \%$ & 1 \\
\hline Sears & $4 \%$ & 1 \\
\hline Willoughby's & $4 \%$ & 1 \\
\hline Other & $4 \%$ & 1 \\
\hline
\end{tabular}


Table 12. Responses of subjects to question $\# 12$ about how long a hearing aid battery should last.

\begin{tabular}{|l|l|l|}
\hline Response categories & Percentage of responses & $\begin{array}{l}\text { Number of } \\
\text { responses }\end{array}$ \\
\hline Don't know/no idea & $40 \%$ & 8 \\
\hline 1 year & $15 \%$ & 3 \\
\hline $2-3$ weeks & $20 \%$ & 4 \\
\hline $1-3$ months & $15 \%$ & 3 \\
\hline 6 months to 1 year & $5 \%$ & 1 \\
\hline Until it quits working & $5 \%$ & 1 \\
\hline
\end{tabular}


Question 13 examined the ability of the subjects to demonstrate knowledge of one important part of a BTE hearing aid, the detachable earmold piece. The earmold is the part that sits in the concha and ear canal, and has a clear tubing that is connected to the hearing aid, which rests behind and atop the pinna. In the results, presented in Table 13, over half of the subjects responded correctly. The rest made incorrect choices or admitted lack of knowledge. Due to the suspicion of terminology difficulties on the part of the subjects, there is the possibility that the subjects were simply not aware of the what the term earmold meant. The few subjects who selected a) with soap and warm water, may have been responding to the literal content of the word earmold.

In Table 14. information obtained in response to a question about how to set and adjust the hearing aid volume is presented. Reviewing the responses in Table 14, it is clear that there was a wide variety of responses. About half of the subjects answered correctly. However, $52 \%$ of the respondents wrote inappropriate answers such as at 3 or best. not all the way on, or don't know. Perhaps the subjects who chose don't know had a weak rationale for their choice in that there is no standard volume control setting for hearing aids. More likely this answer indicates a basic lack of understanding of hearing aids and volume control adjustment. It seems that some of the other responses to this question indicate a low level of knowledge about hearing aids in general, and show that the participants have a limited experience in this area. An example of this could be a adult foster care home resident whose hearing aid is supposed to be set to $\underline{3}$ on the volume control, and the caretaker has then 
Table 13. Responses of subjects about correctly identifying the earmold part of the hearing aid $(n=20)$.

\begin{tabular}{|l|l|l|}
\hline Response categories & Percentage of responses & $\begin{array}{l}\text { Number of } \\
\text { responses }\end{array}$ \\
\hline a) a kind of earwax & $15 \%$ & 3 \\
\hline b) part of a hearing aid & $55 \%$ & 11 \\
\hline $\begin{array}{l}\text { c) the part that makes } \\
\text { sounds louder }\end{array}$ & $5 \%$ & 1 \\
\hline d) don't know & $25 \%$ & 5 \\
\hline
\end{tabular}


made an erroneous assumption about volume control settings for all hearing aids. The best answer was wherever the person is able to hear best. This would be at a setting where hearing is improved, but not to the point where the amplified sound becomes distorted or causes the hearing aid to malfunction. Turning a hearing aid volume control to full on for the best setting usually indicates that the power of the hearing aid is not appropriate for the person's hearing loss, and a new audiologic evaluation with hearing aid examination is in order. Caregivers for the elderly should be able to recognize this important information and to arrange for appropriate measures as a result.

Table 15 presents information about what strategies for increasing communication are appropriate for the subjects and their hearing impaired residents. Based on these results it would seem that most of the subjects chose at least one response that was an appropriate course of action. One area of concern was that not all of the subjects chose all of the appropriate actions.

A variety of strategies for increasing communication with the elderly should be included in the caregiver's training, prior to the actual opening of the adult foster care home. Hearing impairment is only one of many possible problems that need to be addressed in achieving optimal exchange of instructions, requests, and information between resident and caregiver. Chen (1994) suggested that hearing impairment often adds to the difficulties associated with aging of the elderly residents, who often experience cognitive decline. She pointed out that two kinds of cognitive impairment occur with aging: rate of processing of information, and working memory capacity. These deficits create barriers to effective communication when overlaid with 
significant hearing loss. Hearing impairment also leads to poor patient-caregiver consultations (Jinks 1991).

In addition, knowing about different strategies for improving communication may decrease the frustration level of the caregiver, according to Patterson and Dancer (1987). and increase their feelings of empathy toward the resident. Jinks (1991) also found that hearing impaired older adults are more at risk for drug-use problems due to misunderstanding of dosage and timing. Efforts to restore normal communication are even more beneficial in these instances. Based on the results of the answers to question \#15, it would appear that adult foster care home operators are not adequately trained in this area.

According to the data presented at the beginning of this thesis, the expected percentage of hearing impaired persons within an extended care setting for the elderly was $80 \%$. As can be seen from the data in Table 16, estimates of hearing impairment in elderly residents vary widely, and probably reflect a general lack of knowledge as to how to identify hearing loss, effects of hearing impairment, and general information about hearing loss in the elderly. What is most concerning is the 5 subjects who wrote $\underline{0 \%}$ as their answer. It would be interesting to ask this question again following training classes about hearing impairment in the elderly. Perhaps the subjects associate hearing loss with the use of hearing aids, and therefore did not guess accurately based on this perception.

Jinks (1991) found that presbycusic hearing loss affects $60 \%$ of individuals over the age of 65 , and he estimated that $30 \%$ to $50 \%$ of those who are affected have obvious difficulty in communication. Caregivers should be alerted to listen when 
residents complain about poor hearing in noise, increased sensitivity to loud sounds, and difficulty understanding speech.

Another common cause of hearing loss among the elderly is ototoxic drug use (Jinks 1991) and caregivers should be made aware of the major offenders and be alert for signs of hearing deterioration. Early recognition of a drug-induced hearing loss can prevent further damage and may even be reversible. The final question of the survey was designed to determine if the caregivers were aware of community resources for hearing problems, and also to find out if any of the homes has a regular service provider. As presented in Table 17, 75\% do not have access and do not feel, therefore, that this service is within the scope of practice. Only 3 out of 20 provided the name or business name of an appropriate caregiver. Consulting a doctor would eventually also produce a referral for assistance. Over half of the respondents do not choose to take any action in regard to this problem. That may mean that, even if the residents do have noticeable hearing loss, the response to provide follow-up care is not in place. Residents of long term health care settings have a right to access services that would provide benefits to quality of life and improve a significant aspect of daily living, such as communication skills. 
Table 14. Responses of subjects to question \# 14 in regards to the proper setting of the volume control on a hearing aid of a resident of an adult foster care home.

\begin{tabular}{|l|l|l|}
\hline Response categories & Percentage of reponses & $\begin{array}{l}\text { Number of } \\
\text { responses }\end{array}$ \\
\hline $\begin{array}{l}\text { Where the person wants } \\
\text { the volume control set }\end{array}$ & $38 \%$ & 10 \\
\hline $\begin{array}{l}\text { Where the hearing aid } \\
\text { does not squeal }\end{array}$ & $19 \%$ & 5 \\
\hline Do not know/no idea & $15 \%$ & 4 \\
\hline $\begin{array}{l}\text { Where the hearing of the } \\
\text { person is the best }\end{array}$ & $11.5 \%$ & 3 \\
\hline $\begin{array}{l}\text { At a ' } 3 \text { ' or less on the } \\
\text { dial }\end{array}$ & $4 \%$ & 1 \\
\hline At the 'normal' setting & $4 \%$ & 1 \\
\hline $\begin{array}{l}\text { Set on the outside of the } \\
\text { hearing aid }\end{array}$ & $4 \%$ & 1 \\
\hline Not all the way on & $4 \%$ & 1 \\
\hline
\end{tabular}


Table 15. Subjects' responses about using strategies for improving communication with elderly hearing impaired residents of adult foster care homes.

\begin{tabular}{|l|l|l|}
\hline Response categories & Percentage of responses & $\begin{array}{l}\text { Number of } \\
\text { responses }\end{array}$ \\
\hline $\begin{array}{l}\text { a) turn up hearing aid } \\
\text { volume control }\end{array}$ & $13 \%$ & 13 \\
\hline b) shout & $1 \%$ & 1 \\
\hline c) face the person & $16 \%$ & 16 \\
\hline $\begin{array}{l}\text { d) slow down my speech } \\
\text { and use simple words }\end{array}$ & $15 \%$ & 15 \\
\hline $\begin{array}{l}\text { e) use a notepad to write } \\
\text { what I am saying }\end{array}$ & $9 \%$ & 8 \\
\hline f) give up & $0 \%$ & 0 \\
\hline $\begin{array}{l}\text { g) try to use other words } \\
\text { to say what I mean }\end{array}$ & $8 \%$ & 8 \\
\hline $\begin{array}{l}\text { h) inform their family to } \\
\text { have the person's hearing } \\
\text { aids checked }\end{array}$ & $17 \%$ & 17 \\
\hline Do not know/left blank & $1 \%$ & 1 \\
\hline
\end{tabular}


Table 16. Subjects' reponses to question about estimating the percentage of residents with significant hearing loss currently residing in their adult foster care home site.

\begin{tabular}{|l|l|l|}
\hline Response categories & Percentage of responses & $\begin{array}{l}\text { Number of } \\
\text { responses }\end{array}$ \\
\hline $0 \%$ hearing impaired & $20 \%$ & 5 \\
\hline $\begin{array}{l}3 \%-25 \% \text { hearing } \\
\text { impaired }\end{array}$ & $16 \%$ & 4 \\
\hline $\begin{array}{l}26 \%-50 \% \text { hearing } \\
\text { impaired }\end{array}$ & $16 \%$ & 4 \\
\hline $\begin{array}{l}51 \%-75 \% \text { hearing } \\
\text { impaired }\end{array}$ & $4 \%$ & 1 \\
\hline $\begin{array}{l}76 \%-100 \% \text { hearing } \\
\text { impaired }\end{array}$ & $12 \%$ & 3 \\
\hline $\begin{array}{l}\text { Do not know what } \\
\text { percentage of hearing } \\
\text { impaired residents }\end{array}$ & $12 \%$ & 3 \\
\hline
\end{tabular}


Table 17. Responses of subjects about access by hearing impaired residents in adult foster care home settings to hearing health professionals.

\begin{tabular}{|l|l|l|}
\hline Response categories & Percentage of responses & $\begin{array}{l}\text { Number of } \\
\text { responses }\end{array}$ \\
\hline None & $40 \%$ & 10 \\
\hline Family's responsibility & $12 \%$ & 3 \\
\hline $\begin{array}{l}\text { Will take to an M.D. or } \\
\text { audiologist }\end{array}$ & $12 \%$ & 3 \\
\hline Cannot provide & $4 \%$ & 1 \\
\hline Make appt. & $4 \%$ & 1 \\
\hline Willoughby's & $4 \%$ & 1 \\
\hline $\begin{array}{l}\text { Mt. Hood Hearing } \\
\text { Center }\end{array}$ & $4 \%$ & 1 \\
\hline
\end{tabular}




\section{CHAPTER V \\ SUMMARY AND IMPLICATIONS}

Summary

Using a survey, 20 subjects who provide long-term residential care for the elderly in Multnomah County in the state of Oregon were assessed to determine their level of knowledge regarding hearing aids and communication strategies. In a few areas. subjects appeared to have basic skills and techniques, but in most areas, the level of knowledge appeared inadequate and inaccurate. As subjects are the major care provider for elderly residents, the need for more training in this area is clearly indicated.

\section{$\underline{\text { Implications }}$}

Implications that can be drawn from the data collected are limited because of the small sample obtained. The 20 responses that were received required diplomacy and persistence on the part of the investigator. with repeated phone calls to request return. Most of the non-respondents who were contacted by phone declined to participate in the study. Reasons given included a feeling that recent attention by the media had cast an unfavorable light on their operations and they did not wish to participate in any activity that was not required for licensure. Several subjects were very clear about the lack of interest in participating in any more studies at this time. Other subjects clearly did not understand the request due to language problems and simply declined to participate when contacted by telephone. Several of the completed surveys which were returned also showed a lack of writing skills, which obviously made the task more difficult. It can be suggested that a lack of written English does not reflect the ability of the subject to communicate verbally, and that 
more information would have been obtained during an interview. Perhaps a personal interview with subjects would allow for better information retrieval.

Another factor that influenced the data collection was the assumption that all the adult foster care homes on the list provided by the county agent were serving the elderly. Via the phone conversations to encourage the return of the surveys, it was discovered that some of the homes are designated for persons who are mentally disabled or emotionally disturbed, who are often younger and healthier. These subjects returned their surveys, without completing them, and several phoned to report this situation. A screening telephone survey prior to the sending of the surveys would have revealed this information, and helped to direct the surveys to the appropriate subjects.

Other than these factors, the data collected shows clearly that the subjects, adult foster care home operators, are lacking in knowledge about the use, function, and maintenance of hearing aids, and are unsure about how to improve communicative interactions. In the preparation prior to operating a care home, operators, and staff members should be required to take courses in these important topics. The data obtained in this thesis may be used to construct a training program to be offered in the tri-county area under study. At present, adult care home operators are required to complete 10 hours of continuing education each year, and it is hoped that the importance of choosing the training courses in hearing and communication sciences will be emphasized.

Adult foster care homes in Oregon have come under great scrutiny in the past few years, with government agencies carefully reviewing sites for potentially lifethreatening situations. However, the excessively rapid rate of expansion of these 
sites and the cutbacks in public funding have resulted in an inability on the part of the public monitors to give attention to other issues, such as the need to educate caregivers about the importance of communication skills. Recognizing hearing impairment in, adjusting and assisting with hearing aids of. and improving communication with the elderly adult foster care home resident has not been a priority for either the governing agencies of the tri-county area or the home operators in the past. The implicit understanding is that there are higher priorities such as safety, sanitation, and security. It is time to factor into the training courses issues of comfort, emotional support, optimal physical and mental health, and simple human satisfaction with life.

\section{Recommendations:}

Based on the findings of this study, a training program has been designed and is recommended to be offered to adult foster care home operators in Multnomah County. As it has been stated in previous passages, each employee at an adult foster care home is required to obtain 10 hours each calendar year of additional training. Appendix $\mathrm{C}$ is a brief outline for a training class that would provide 2 hours of training credit for the attendees. Following successful completion of the course, attendees should be able to correctly complete the survey designed for this study. 
References

Anderson, M., Dancer, J. \& Durand, C. (1990). Self perception versus associate's perception of hearing handicap in adults over the age of fifty. The Volta Review, 37, 293-301.

Brannon, M. S. (1992). Strategies for improving nursing home care. The Journal of Long Term Care Administration, Fall/Winter, 18-20.

Brannon, D., Smyer, M., \& Cohn, M. (1992). Strategies for improving nursing home care: A research roundtable. The Journal of Long-Term Care Administration, winter, $18-20$.

Campbell, (1992). Detection of anxiety. Unpublished doctoral dissertation. California State University, Fullerton, volume 31, Issue 0. Page 0930.

Chen, H. (1994). Hearing in the elderly. relation of hearing loss, loneliness, and self-esteem. Journal of Gerontological Nursing. 20(6), 22-8.

Ciurlia-Guy, E., Cashman, M., \& Lewsen, B. (1993). Identifying hearing loss and hearing handicap among elderly people. Gerontologist, $33,644-9$.

Cohen, G. (1987). Speech comprehension in the elderly: the effects of cognitive changes*. British Society of Audiology, 21, 221-226.

Etienne. (1990). Life satisfaction if hearing impaired elderly persons. Southern Illinois University at Carbondale. Part B, Volume 52, Issue 8, page 4107.

Iler, K., Danhauer, J. \& Mulac, A. (1982). Peer perceptions of geriatrics wearing hearing aids. ASHA, $\underline{47}, 433-438$

Jinks, M.J. (1991). Counseling older adults with hearing impairment. Journal of Practical Nursing, 41 . 43-51. 
Katz, J. (1994). Handbook of Clinical Audiology, 4th Edition, p. 569, Willians \& Wilkins, NY, NY

Kleiman. M. (1990). Foster families for adults: a community alternative in long term care. International Journal of Aging and Human Development, 30 (1), 77-78.

Kochkin, S. (1996). Ten year trends in the hearing aid market-has anything changed? The Hearing Journal, $49(1), 23$.

Kreeger, J., Raulin, M., Grace, J., \& Priest, B. (1995). Effect of hearing enhancement on mental status ratings in geriatric psychiatric patients. American Journal of Psychiatry, 152 (4), 629-31.

Linblade, D., \& McDonald, M. (1985). Removing communication barriers for the hearing impaired elderly. MEDSURG, 4. 379-85.

Mahoney, D. F. (1992). Hearing loss among nursing home residents. Clinical Nursing Research, 1, 317-333.

Mahoney, D. F. (1993). Cerumen impaction: Prevalence and detection in nursing homes. Journal of Geriatric Nursing, 19, 23-30.

Martin, F., Krueger, J., \& Bernstein, M. (1990). Diagnostic information transfer to hearing-impaired adults. Texas Journal of Audiology and Speech Pathology, 16, 29-32.

Matteson, M.A. (1993). Vision and screening in cognitively impaired older adults. Geriatric Nursing, 14. 294-297.

McBride, W., Mulrow, C., Aguilar, C., \& Tuley, M. (1994). Methods for screening for hearing loss in older adults. American Journal of the Medical Sciences, 307, 40-42.

Miller, L. (1995). Changes needed in adult foster care. Oregon Nurse, 60 (1), 14. 
Mulrow, C. D. (1991). Screening for hearing impairment in the elderly. Hospital Practice, 26. 79-86.

Newman, D. (1990). Assessment of hearing loss in elderly people: the feasibility of a nurse administered screening test. Journal of Advanced Nursing, 15, 400-409.

Patterson, K., \& Dancer, J. (1987). Alternatives in aural rehabilitation: provider training of nonaudiologists in the delivery of hearing-aid support services to older persons with hearing loss. Educational Gerontology, 13, 487-495.

Quinn, K.S. (1986). Self, spouse and audiologist evaluation of hearing impairment and hearing. Unpublished Master's Thesis. University of Michigan, DAI, Part B. Volume 47, Issue 3.

Schow, R., \& Nerbonne, M. (1980). Hearing levels among elderly nursing home residents. Journal of Speech and Hearing Disorders, 45, 124-32.

Stark, A., Kane, R., Kane, R., \& Finch. M. (1995). Effect on physical functioning of care in adult foster homes and nursing homes. Gerontologist, 35 (5), 648-655.

Stream, R., \& Stream, K. (1980). Focusing on the hearing needs of the elderly. Journal Academy of Rehabilitative Audiology, 13, 104-108.

Swagerty, D. (1995) Geriatric grand founds: hearing impairment and functional independence. Kansas Medicine, 96 , 147-8.

Taylor, K. (1993). Geriatric hearing loss: management strategies for nurses. Geriatric Nursing, 14. 74-76.

Thompson, M.E. (1993). Aging, hearing loss, and hearing aids: myths revisited. American Rehabilitation, 19(4), 20-24.

Trumble. S., \& Piterman. L. (1992). Hearing loss in the elderly. A survey in general practice. Medical Journal of Australia. 157(6), 400-4. 
Warshaw, R. (1992). The shame of America's board-and-care homes. New Choices for Retirement Living, 32(10), 58-62.

Weinstein, B., \& Ventry, J. (1982). The hearing handicap inventory for the elderly. A new tool. Ear and Hearing, 3(3), 128-134.

Weinstein, B., Spitzer, J., \& Ventry, I. (1986). Test reliability of the HearingHandicap Inventory for the Elderly. Ear and Hearing, 3(3), 128-134.

Weinstein, B. E. \& Ventry, I. M. (1983). Audiometric correlates of the hearing handicap inventory for the elderly. Journal of Speech and Hearing Disorders, 48, 379-84. 
Appendix A

Informed Consent Form

I. , agree to take part in this research project on (date). I understand that the study involves completing and returning a survey. The completion time of this survey should take about 15 minutes. Marsha Johnson has told me the purpose of this study is to collect data about the level of knowledge of caretakers of the elderly about hearing aids.

I. may not receive any direct benefits from his study. But the study may increase knowledge in this area and may help others in the future.

Marsha Johnson has offered to answer any questions about this study and what I am expected to do. She has promised that all information I give will be kept confidential and that my name will not be used in this study.

I understand I do not have to take part in this study and that I may withdraw at any time. I have read and understand the above information and agree to take part in the study.

Date: Signature:

Portland State University, P.O. Box 751, Portland, Oregon 97205

(Audiology Dept.: Attention: Marsha Johnson)

If you have concerns or questions about this study, please contact the Chair of the Human Subjects Research Review Committee, Research and Sponsored Projects, 105 Neuberger Hall, Portland State University, (503) 725-3417. 
Appendix B

Adult Foster Care Home Survey: Hearing Aid Knowledge $\quad 6 / 96$ Please complete and return in enclosed, stamped envelope ASAP.

Total number of years working with foster care

Total number of hours or credits in training completed, related to your work in an adult foster care home setting

Total number of residents at site using hearing aids

1. Describe your experience in working with hearing aids?

2. How confident are you in handling hearing aids? (circle one)

Confident Somewhat confident Not confident

3. I feel that handling a hearing aid...

(Circle all that apply)
a) makes me nervous.
b) might damage it.
c) is part of my job.
d) is not part of my job.

4. In your experience, people may not wear their hearing aid because (write your answer):

؟. Draw a line from the parts of the hearing aids to the names.
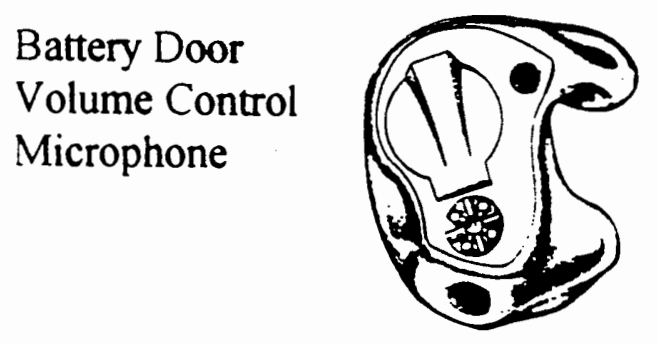
Battery Door
Volume Control
Microphone

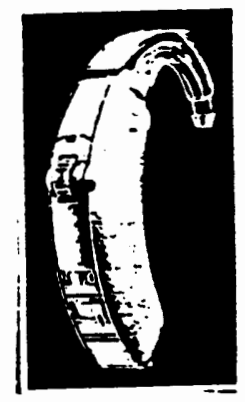


6. Are you comfortable in putting in and taking out hearing aids from residents' ears?

Describe any concerns about this procedure:

7. The best way to clean a hearing aid is:

a) with soap and warm water

b) with a commercial cleaner and dry rag

c) with a tissue or paper towel

d) soak them, and then dry

e) they shiouid noi be cleanled

8. Squealing or whistling of hearing aids means:

9. If a resident's hearing aid is broken, where should it be sent for repair?

10. Describe how to insert a hearing aid battery:

11. Where can you purchase batteries?

12. About how long should a battery last? 
13. An earmold or an ear piece is:

a) a kind of earwax

b) part of a hearing aid

c) the part that makes sounds louder

d) don't know

14. Where should the volume control be set on a hearing aid?

15. When a resident seems to be hard of hearing, I should: (circle all that apply)

a) turn up their hearing aid volume control

b) shout

c) face the person

d) slow down my speech and use simple words

e) use a notepad to write what I am saying

f) give up

g) try to use other words to say what I mean

h) inform their family to have the person's hearing aids checked

16. In your current work setting, what percentage of your patients seem to have a significant hearing loss? (a significant hearing ioss creates some problems with communication).

17. Does your adult foster care home at this time provide any access for the residents to a hearing health professional (audiologist or hearing aid dispenser) on a regular basis? If yes, provide specific information. 


\section{Appendix C}

Overview: Hearing Aids: Part 1
A. Anatomy of Ear: Physics of Sound
B. Review of Hearing Loss: Types, Prevalence, \& Effects
C. Demonstration of Hearing Impairment: Simulations
D. Introduction to Hearing Aids: Examination, Varieties

\section{Hearing Aids: Part 2}

E. Hearing Aids:

Batteries

Volume Control

Troubleshooting Repairs

Cleaning Maintenance

Insertion/Removal tips

F. Communication Strategies with Hearing Impaired: Role Playing \& Practice Introduction of Pocket Talker, Personal Amplifier Systems

G. Community Access to Hearing Resources

PSU Hearing Aid Bank

Audiology Services

Aural Rehabilitation Clinics 